\title{
Elementos para a crítica do jornalismo moderno: Conhecimento comum e indústria cultural
}

\section{RESUMO}

O texto esboça as linhas gerais ou bases teóricas de uma atitude crítica e reflexiva em relação ao jornalismo moderno. O primeiro lance ressalta o caráter contraditório do processo de surgimento do conhecimento comum nos tempos modernos. O seguinte examina a maneira como esse processo foi mediado pelo desenvolvimento do jornalismo e revela as reflexões a que ele deu origem. O terceiro momento relativiza crítica e dialeticamente essas teorias, pregando a necessidade de entender o assunto no contexto mais amplo de conversão da indústria cultural em sistema, verificado no século XX.

\section{PALAVRAS-CHAVE}

Jornalismo moderno

Conhecimento comum

Indústria cultural

\section{ABSTRACT}

This article outlines the theoretical ground from which we may develop a critical and reflexive attitude in front of modern journalism. In the first step, we highlight the antagonistic character of the common knowledge arisen in modern times. In the second, we examine the way this process was mediated by the press and the theoretical reflections about it this process gave place. Finally, we think critical and dialectically these theories, arguing that modern journalism must be understood in the broader context of conversion of culture industry in system, verified in 20th Century.

\section{KEY WORDS}

Modern journalism

Common knowledge

Culture industry

\section{Francisco Rüdiger}


Provém da Escola de Frankfurt a proposição segundo a qual as comunicações modernas se desenvolvem no marco de uma dialética: elas conscientizam tanto quanto reificam os seres humanos, visto serem expressão do enredamento de sua história entre os pólos do progresso e da barbárie $^{1}$. As comunicações se transformaram em veículo das principais relações de poder na sociedade contemporânea, mas também contêm, por isso mesmo, forças e pontos de apoio capazes de nutrirem a criação de processos de vida alternativos e inovadores em relação ao sistema dominante.

\section{A reflexão crítica sobre os fenômenos de} comunicação constitui em si mesma um fragmento de práxis transformadora que, com isso, colabora com os esforços no sentido de desenvolver a dimensão iluminista da mídia, por maiores que sejam os obstáculos

Diante das mesmas, comporta-se como crítico, portanto, aquele que desenvolve uma análise das contradições de seu processo de posição no mundo histórico, em vez de buscar sua purificação ou sustentar a nostalgia do retorno a algum estado idílico passado. A reflexão crítica sobre os fenômenos de comunicação constitui em si mesma um fragmento de práxis transformadora que, com isso, colabora com os esforços no sentido de desenvolver a dimensão iluminista da mídia, por maiores que sejam os obstáculos².

No capitalismo, a criação cultural serve ao espírito de utopia ao mesmo tempo em que o põe a serviço do mercado. Nenhuma ação está completamente isenta da atitude mercadológica da indústria cultural. Por isso, a crítica é uma atividade que, embora sujeita a seu feitiço, se dirige tanto contra aqueles que defendem a pureza e integridade das formas superiores dos bens culturais, quanto contra aqueles que defendem os benefícios de seus vários subprodutos mercadológicos. Atualmente, a contestação do kitsch popularesco não é mais importante do que a denúncia das pretensões fraudulentas tantas vezes presentes no vanguardismo. $\mathrm{O}$ consumo de um e de outro cada vez menos se distingue totalmente dos prazeres do consumo de qualquer outro bem disponível no mercado.

Quando bem pensada, verifica-se que a cultura, elevada ou não, em geral, sempre contém um momento de barbárie, tanto quanto um eventual momento de emancipação em relação ao sistema social estabelecido. O ponto só pode ser decidido por pesquisa e julgamento, não há como resolvê-lo por princípio. O esclarecimento não teria se propagado sem o desenvolvimento das comunicações. A reprodução dos ideais iluministas por parte delas, todavia, não pode ser separada de sua crescente reificação mercantil, de sua subordinação aos esquemas da indústria cultural.

Desde o final do século XIX, o capitalismo se imiscui de forma direta no campo da cultura, fundindo todos os seus elementos em um só movimento. O resultado é a transformação da indústria cultural, prática bem mais antiga, em sistema cada vez mais enraizado e abrangente. A democratização da cultura ensejada pela economia de mercado foi redirecionada pela atitude empresarial, e a contrapartida de sua difusão em massa é a perda de seu conteúdo formativo e sentido emancipatório, conforme se pode ver examinando a fortuna do conhecimento comum, ordinário, na contemporaneidade.

\section{A Dialética da informação}

Para Adorno, o esclarecimento "se encontra mais difundido hoje do que em tempos passados, e isto significa que na atualidade camadas da população que em outra época não tinham acesso à cultura e ao saber estão em contato com as artes e as ciências graças aos meios de comunicação". Em contrapartida, verifica-se através deles uma tendência à redução estrutural na consciência esclarecida, cujo principal aspecto - no plano cognitivo - é a perda ou falta do elemento de síntese que poderia torná-la produtiva entre as massas, em virtude do seu aprisionamento às formas mercantis mais massificadas.

A contradição entre a emancipação do espírito crítico e seu concomitante enredamento em esquemas que o anulam é característica de nossa era, na medida em que, nela, a mercantilização das relações que possibilita o aparecimento do primeiro acaba por se imiscuir em sua própria esfera e, assim, a fazer com que o consumo tome o lugar da criatividade, com que "a informação tenda a substituir a penetração e a reflexão intelectuais" 3 .

Conforme foi dito, a formação das redes de comunicação e a expansão dos meios de saber é um produto do progresso, que desperta e idiotiza as pessoas ao mesmo tempo. A avaliação 
do processo não pode ser abstrata. A verdade a seu respeito não reside apenas em seu núcleo racional: a propagação do conhecimento. As conexões objetivas em que aquele processo se enreda realidade histórica também precisam sem levadas em conta.

Nesse sentido, as referidas redes podem ser vistas, por um lado, como fator que colaboram decisivamente para tornar o homem adulto, fazendo-o mais racional, lúcido, informado e habilidoso. As pessoas de nosso tempo tendem a aceitar o que tem de ser aceito, rejeitando o que não pode ser provado como superstição. Por outro lado, porém, elas se sujeitam, assim, a uma indústria da cultura, no contexto da qual essas redes servem de meio para distraí-los da própria vida, afastando da mente de muitos, talvez da maioria, as mudanças que teriam de fazer em seu mundo e seu modo de ser, para viver de acordo com suas inclinações mais individuais.

As comunicações, sim, ajudaram o indivíduo a conquistar liberdade de opinião significativa e servem de veículo de uma opinião pública que, apesar de tudo, várias vezes, mas nem sempre, ajuda evitar o pior, conservando de algum modo suas funções emancipatórias. O progresso das mesmas é algo que se liga a um processo ainda mais amplo, que é o do desenvolvimento das estruturas cognitivas e dos estoques de saber socialmente compartilhadas.

Visando entender melhor esse processo, é preciso relacioná-lo com o fato de que, com a era moderna, o conhecimento comum se tornou objeto de renovação constante e de alcance cada vez mais amplo, via o desenvolvimento de sucessivos meios de comunicação mas, sobretudo, da expansão das práticas jornalísticas. $\mathrm{O}$ conhecimento comum, cotidiano, lembremos, é elaborado em meio à prática coletiva como apropriação das conexões em que se articula o mundo social e histórico ${ }^{4}$. A figura, todavia, tem baixo índice de especialização, enquanto as estruturas que lhe subjazem conservam um caráter comunitário, de modo que, nessa situação, o movimento de formação da opinião e consciência comum tende a ter um cunho imediato e monolítico, a não se expressar como opinião elaborada ou saber individualizado, mas antes como consenso coletivo imposto tradicionalmente.

Os tempos modernos importam, por razões que não é possível explicitar aqui, numa ruptura com esse registro do saber ordinário, na sua passagem para o plano de um conhecimento acionado e reativado periodicamente por instituições especializadas, cujo coletivo acabou sendo chamado de imprensa e, mais recentemente, de mídia. A expansão da economia de mercado, primeiro, criou as condições para a diferenciação do saber, ao mesmo tempo em que começou a submeter sua difusão a um protocolo mercadológico. $\mathrm{O}$ passo seguinte foi minar as bases que asseguravam o consenso coletivo, oportunizando o surgimento de situações vinculadas a diversos pontos de vista ou opiniões e em que aquele só por exceção é alcançado.

Embora não limitado a ele, o processo é, como dito, ininteligível, sem a consideração do papel que nele desempenha a publicação de impressos mas, sobretudo, o desenvolvimento do jornalismo desde o final do século XIX. Origina-se dos pioneiros do estudo do jornalismo a conclusão, relativamente consensual ainda hoje, de que este é uma criação da era burguesa. $\mathrm{O}$ aparecimento da atividade está ligado à transformação dos impressos em material de leitura e bem de consumo desse grupo social. A formação intelectual e os projetos de ascensão política em meio às quais surgiu exigiram o seu contínuo desenvolvimento. O público leitor surgido com sua era está dialeticamente ligado à expansão da atividade editorial, à crescente publicação de livros e periódicos, à formação de um mercado de bens culturais.

$\mathrm{Na}$ Europa, havia impressos circulando publicamente desde o final do século XV: livros, volantes, editais, revistas, almanaques, mas só dois séculos mais tarde o recurso técnico que os criou, o prelo manual, começaria a dar lugar ao que entendemos por jornalismo. No começo do século XVIII, efetivamente aparecem as primeiras redações e se começa a publicar folhas diariamente de modo regular. A sociedade burguesa se expande e em seu meio vai surgindo uma esfera pública, que se articula para discutir os fatos políticos e seus próprios interesses através, entre outros meios, dos impressos. O conteúdo desses é variado e não perde de vista as conexões com o mercado, mas sua a forma de expressão é literária e o sentido, predominante político.

A paulatina desterritorialização da consciência promovida pela expansão das atividades mercantis é intermediada pelo aparecimento de veículos de comunicação que a socializam, engendrando um circuito permanente e cada vez mais amplo de renovação e reestruturação da experiência em diferentes níveis. A expansão, 
primeiro e, em seguida, a especialização em vários segmentos desses veículos está embutida em todo esse desenvolvimento, conforme ele assume feições duradouras na época em consideração (século XVIII).

Nesse período inicial, a prática do jornalismo, todavia, era predominantemente política e estava submetida à ação propagandística. A expansão do capitalismo se deu em tensão com a concentração do poder político no aparelho de estado. A propaganda governamental e o debate de ideias pautavam a conduta dos publicistas. Os periódicos eram veículos de propaganda e embates doutrinários; seus responsáveis, homens que aspiravam ou pertenciam à classe política. A sociedade civil burguesa se constitui em meio a esse confronto e é em meio à agitação publicística que se desmorona o absolutismo e o Antigo Regime.

Depois de lutar contra os privilégios monárquicos e vencer a censura estatal, as reivindicações burguesas de liberdade intelectual, cuja origem era, aliás, religiosa, entrementes foram se consolidando em um aparato constitucional. $\mathrm{O}$ estado liberal burguês, aos poucos, firmou suas instituições e, com elas, o direito à liberdade de expressão. As estruturas cognitivas do público sintonizado com essas mudanças avançaram com a nova situação. Desde o século das Luzes, com efeito, verificou-se uma formidável expansão do conhecimento público. O crescimento em variedade e a difusão em maior número de material impresso forneceram as condições para uma rearticulação da consciência burguesa. O principal e distintivo, porém, é o aparecimento de um espírito crítico de caráter público, o crescimento da discussão e o estímulo à formação de opinião sobre os acontecimentos que afetam os destinos da vida em sociedade.

No final do XIX, o panorama mais amplo, todavia, já mudara e, entrando no século seguinte, houve rápidas e profundas transformações, que fizeram a vida social transitar do regime burguês para o tecnocrático. Elas acabaram com a ordem liberal e nos jogaram no mundo democrático de massas. Conforme o saber e as opiniões iam se convertendo em mercado explorado por empresas jornalísticas, o conhecimento público mais e mais se foi tornando prisioneiro dos seus fetiches, conforme já se tinha claros sinais a respeito no tempo de Balzac.

Durante o século XIX, a possibilidade de tratar o público como clientela consumidora e a demanda por veículos de publicidade para expandir os negócios conduziram à mercantilização da imprensa, o principal fator responsável por sua crescente concentração nas mãos de umas poucas empresas e conglomerados no período seguinte. Os empreendimentos jornalísticos foram historicamente, portanto, os primeiros a explorar o mercado dos bens simbólicos como indústrias organizadas, mas isso, vale lembrar, é um desenvolvimento mais recente em relação às suas origens remotas.

Conforme nota Habermas, os primeiros jornais merecedores do conceito "resguardavam para as suas redações aquela espécie de liberdade que era, de um modo geral, característica para a comunicação das pessoas privadas enquanto público [na era burguesa]"5. As preocupações políticas preponderavam sobre as perspectivas de tirar vantagens econômicas com o negócio editorial. Para fazer frente à crescente concorrência, os veículos jornalísticos, contudo, tiveram de começar a se organizar como empresas. Depois, o tempo foi o que bastou para os empresários do setor descobrirem nas experiências de jornalismo popular que haviam se posto em marcha algumas décadas antes um modelo de expansão para seus negócios.

No final do século XIX, esse processo de todo modo parece concluído, conforme indicam os vastos mercados consumidores de impressos surgidos na Europa e Estados Unidos. As publicações políticas e partidárias entraram em declínio, para depois vir a desaparecer. As empresas que não criaram veículos populares para atender os mercados de massas, surgidos com as reformas trabalhistas e a escolarização obrigatória, pelo menos seguiram a tendência no sentido de abandonar a linguagem literária. $\mathrm{O}$ positivismo tecnocrata em voga nesse novo contexto ensejou o aparecimento do estilo propriamente jornalístico, que acabaria por se impor após a I Guerra Mundial.

Nessa época, o jornalismo, por outro lado, concluiu também seu processo de profissionalização. As críticas a seu emprego propagandístico durante o conflito ${ }^{6}$, mas também nos conflitos entre capital e trabalho, provocaram seus sujeitos a elaborar e adotar um sucedâneo da doutrina positivista do conhecimento. A preocupação em parte cínica, em parte ideológica em preservar o negócio, levou ao surgimento de um código deontológico próprio, cujo cerne era o compromisso de bem informar a sociedade. O empirismo espontâneo que se impusera no período anterior, 
a crença ingênua de que o periódico se resume em reportar os fatos para os seus auditórios, foi reformada em bases doutrinárias.

Destarte, triunfou o formato noticioso, sugerido pelo crescente emprego do telégrafo, desde o final do século XIX. Os princípios fordistas estavam se transplantando para o campo jornalístico. A espontaneidade passou a ser mais reprimida. A reportagem foi caindo para um segundo plano. As redações passaram para um novo patamar de sociabilidade. O regramento da atividade se enrijeceu, com o surgimento dos manuais de redação, a formação especializada e outras exigências de profissionalização que não tiveram outro sentido senão se acentuar mais tarde, quando o jornalismo passou a ser praticado nas empresas de rádio, revista e televisão.

\section{Poder à forma de saber}

Quando se busca entender como esse processo se estruturou teoricamente, construir os conceitos que permitam esquematizá-lo em termos mais abstratos, a pesquisa via de regra se depara com uma ou outra versão ou teoria do que chamaremos de paradigma do $4^{\circ}$. Poder. Oriundo talvez de Burke (1787) e popularizado por Carlyle (1841), o termo surgiu com sentido ambíguo entre os intelectuais conservadores, para indicar a influência da imprensa no processo de formação da opinião pública e na condução dos negócios políticos de nosso tempo. A consagração do princípio, contudo, foi obra dos pensadores liberais.

Para eles, os periódicos populares, sempre que não são controlados pelo estado, cumprem um papel vital para a sociedade, que é o de fiscalizar as ações dos governantes. Através da imprensa, a sociedade as traz à luz, mantém sob controle e faz saber aos seus agentes seu pensamento sobre os assuntos de interesse público. "Tornou-se uma trivialidade política afirmar que quem governa o mundo é a opinião pública" e que esta é formada "por homens que estão mais ou menos à altura dos demais e que se dirigem a esses últimos por meio dos jornais", dizia Stuart Mill, em $1859^{7}$.

Quando a era liberal entrou em colapso, na virada para o século $X X$, o entendimento do poder que a imprensa representava, entretanto, passou a ter mais um sentido: os periódicos começaram a ser visto como meios de sustentar uma política de estado, aquela defendida por seus proprietários. Para as forças sociais emergentes, os periódicos são, sim, expressão da sociedade civil, mas sua principal função não é fiscalizar o poder de estado e assegurar que seus atos expressem a opinião pública.

Os jornais são empresas controladas pelos setores sociais e econômicos mais fortes, que deles se servem para sustentar as coalizões políticas de seu endosso e conduzir os processos de formação da vontade e expressão ideológica de acordo com seus interesses. Subjacente nos escritos dos clássicos da social democracia, a tese aparentemente começou a ser explorada de maneira mais sistemática por Heinrich Wuttke, Karl Kraus, Upton Sinclair e George Seldes, para ser elaborada teoricamente nos escritos de Norman Angell e Antonio Gramsci.

Para o primeiro autor, os jornais são "meios públicos de informação, de seleção e apresentação dos fatos que chegam às pessoas, de provimento do conhecimento que determinará sua opinião e atitude política", cujo controle e emprego, entendido em termos de "instrumento", está "nas mãos de uma pequena claque de grandes capitalistas, estreitamente ligada em interesses (via a publicidade) aos demais grupos de capitalistas". Afinal, remata o segundo,

O exercício normal da hegemonia [de uma classe social], no terreno clássico do regime parlamentar, caracteriza-se pela combinação da força e do consenso, que se equilibram variadamente, sem que a força suplante o consenso, ou melhor, procurando obter que a força pareça apoiada no consenso da maioria, expresso pelos chamados órgãos da opinião pública - os jornais e as associações ${ }^{8}$.

Deixando de lado a tarefa que seria reconstruir a trajetória desse entendimento conjunto durante o último século, verifica-se que sua raiz comum, qualquer que seja a versão, é a atribuição à imprensa de um poder mediador sobre a condução dos assuntos políticos da sociedade. Entre os pensadores liberais, os periódicos seriam expressão do poder da sociedade civil sobre o estado, enquanto seus antípodas socialistas argúem que eles antes expressam o poder dos grupos dominantes, senão sobre o estado, pelo menos sobre a maioria da sociedade.

O problema com essa visão é, em primeiro, sua relatividade histórica e, em segundo, sua falta de especificidade conceitual. O jornalismo, ninguém negará, se desenvolveu a reboque do curso seguido pela vida política. As folhas de vários tipos foram por muito tempo órgãos de partidos. 
O panorama, contudo, começou a mudar, há mais ou menos um século, e chegou ao ponto de hoje não mais conhecer a figura do jornalismo políticopartidário.

A sociedade capitalista transitou, com o tempo, para uma nova etapa, em que consciência civil e ação política, categorias fundadoras da era burguesa, parecem estar se tornando anacrônicas. O jornalismo, sem dúvida, segue agenciando processos de poder e estes se consubstanciam na ficção eficaz que é a opinião pública. $\mathrm{O}$ fato, porém, é que esta opinião, passando a ser elaborada a partir da circulação de material noticioso, não mais surge da forma que era o caso quando o centro das atividades jornalísticas era o texto doutrinário 9 .

Dentro do novo contexto e contrapondo-se a essa visão, predominante do ponto de vista do conjunto das reflexões sobre o assunto, surgiu com o tempo um outro paradigma de entendimento do jornalismo. A revolução empresarial que o subordinou à racionalidade mercadológica, consagrando o estilo noticioso, impactou também em suas formas de reflexão. Desde sua consolidação, o jornalismo fora visto em seu significado coletivo, sobretudo, sob a ótica da filosofia política e, assim, como prática inserida no campo das relações de poder entre estado e sociedade. Coube a Adelmo Genro Filho, entre outros, talvez, sistematizar uma mudança de perspectiva para o campo do saber e, assim, subordiná-lo a ótica da sociologia do conhecimento.

Explorando as pistas deixadas por Robert Park ${ }^{10}$, o autor propõe que vejamos o jornalismo moderno, sobretudo, como uma forma de conhecimento da realidade. $\mathrm{O}$ conhecimento especializado oriundo das ciências e que permanece em boa parte esotérico tem contrapartida no conhecimento ordinário mais ou menos livre, aberto e universal proporcionado pelas atividades jornalísticas. Os profissionais de imprensa ainda hoje professam a filosofia espontânea de que seu trabalho consiste apenas no registro imediato dos fatos e em seu relato empírico para o público supostamente interessado, conforme certos princípios, que seriam, em resumo, a objetividade, a imparcialidade e o equilíbrio de pontos de vis$\mathrm{ta}^{11}$.

O jornalismo, porém, chama à atenção esta escola, é bem mais que isso, se levarmos em conta seu modo de inserção na estrutura social mais abrangente. A consideração do assunto desde este ponto de vista o converte em uma mediação do processo social de elaboração coletiva do conhecimento comum dos agrupamentos humanos e, avançando um pouco mais, da própria construção de seu mundo histórico. O jornalismo é uma forma social de conhecimento que ultrapassa a base social imediata que o promoveu, isto é: o capitalismo, porque corresponde a necessidades sociais mais profundas e "que, teoricamente, independem das relações mercantis e capitalistas, embora tenham sido nascidas de tais relações e por elas [foram] determinadas" 12 .

A perspectiva, sem dúvida, representa um avanço na reflexão sobre o jornalismo, ao lembrar, a seu modo, que este, antes de ser uma agência de poder político, é uma mediação da consciência cotidiana. A abordagem também possui o mérito de ser afinada em termos de consciência histórica, salientando o fato de que esse entendimento se aplica, sobretudo, para as formas de jornalismo contemporâneo. O enfoque só se aplica com prejuízo ao jornalismo clássico, em que predomina o discurso literário, o texto de opinião e a perspectiva doutrinária. $\mathrm{O}$ compromisso com a elaboração do conhecimento comum que nele se apresenta é próprio de sua etapa avançada, do momento em que ele se organiza como empresa e se insere no âmbito do capitalismo massificado.

O problema com essa visão, contudo, se apresenta e, em nosso entendimento, consiste em seu déficit de reflexão crítica sobre o estatuto da atividade jornalística neste contexto. O reconhecimento da função cognitiva exercida pelo jornalismo em nosso meio precisa ser considerado criticamente, sem ilusões, mantido a certa distância. À sociologia do conhecimento que lhe subjaz caberia reconhecer que o saber, tanto quanto o poder agenciado pelo jornalismo é, agora, articulado socialmente por meio do mercado.

Afinal, as comunicações, é certo, contêm um momento de liberdade, permitindo ao indivíduo elaborar seu próprio conhecimento, pensar suas próprias idéias, não professar o credo dominante mas, por outro lado, são expressão de relações objetivas, que modelam sua existência e pensamento, antes mesmo dessas idéias chegarem à sua consciência, sendo parte ou momento daquilo que, recorrendo à linguagem conceitual, estamos chamando de sistema da indústria cultural.

Adelmo Genro teve o mérito de recuperar o caráter e explorar com seriedade o aspecto cognitivo contido na atividade jornalística. Para ele e seus seguidores, o jornalismo é uma forma de produção de conhecimento, tanto quanto 
uma mercadoria explorada empresarialmente. Porém, falta, em nosso juízo, a percepção de que se, por um lado, o jornalismo não é sinônimo de manipulação ${ }^{13}$, embora isso possa ocorrer por meio dele, nem se reduza a um negócio, porque veicula um saber, esse saber não é puro e simples conhecimento.

O conhecimento puro e simples é uma abstração: efetivamente, ele é tão histórico quanto todo o resto que nos é próprio ${ }^{14} \mathrm{e}$, no caso em foco, não apenas porque o conhecimento ensejado pelo jornalismo seja o do singular, factual, mas antes porque se trata de um conhecimento essencialmente determinado pelo desenvolvimento do capitalismo.

O serviço público que, segundo seus portavozes, o jornalismo presta é ideologia, quando não falsa consciência esclarecida ${ }^{15}$, porque o jornalismo de fato engendra e veicula um saber, mas esse não é um saber objetivo e imparcial, nos termos pretendidos por sua doutrina profissional e positivista. $\mathrm{O}$ conhecimento jornalístico é tal apenas do ponto de vista do mundo capitalista: efetivamente, e por mais contradições que contenha ${ }^{16}$, ele é engendrado de acordo com a racionalidade mercadológica, e não em resposta a uma pretensa necessidade antropológica, como sugere Genro.

Do ponto de vista da história do conhecimento comum, o fundamental é reconhecer, portanto, que, se o jornalismo se tornou uma de suas principais mediações, não a única por certo, é por seu intermédio que aquele se tornou cada vez mais prisioneiro da forma mercadoria.

O jornalismo precisa ser visto como uma atividade intelectual que, em termos cognitivos, constitui a mediação de dois processos. O primeiro é a ampliação, via o saber, do círculo social ou mundo histórico em que vive o sujeito. O segundo é a diferenciação dos graus de elaboração do conhecimento desse processo. A atividade jornalística tem a ver com a imposição de novos fatos à consciência tanto quanto com a necessidade de conhecimento a seu respeito.

A síntese disso é a criação de um desejo geral de saber, que, conforme avança o capitalismo, todavia, passou a ser agenciado de forma profissional e mercantil por empresas especializadas e assim, embora agencie processos de conhecimento, o faz submetido ao fetiche da forma mercadoria.

\section{Jornalismo e indústria cultural}

Desde o século XIX, o jornalismo, com efeito, foi se convertendo em importante fonte de conhecimento público sobre os fatos que ocorrem no mundo, mas ao mesmo tempo o saber assim mediado foi passando mais e mais a cair na órbita do fetichismo da mercadoria. O título pelo qual esse conhecimento atende passou a se chamar, por essa época, de notícia e, mais tarde, de informação. A notícia ou informação é o resultado do processamento dos fatos relevantes para um ou mais grupos sociais, de acordo com uma técnica que visa colocá-lo no mercado. A empresa comprometida com a exploração dessa atividade como negócio se tornou o que hoje chamamos de jornalismo.

Destarte, acontece desde então, porém, um processo no sentido das matérias redacionais de relevância pública, colonizadas pelo valor de troca no mercado, estarem recuando diante das de interesse humano. Noutros termos, verifica-se, inclusive nos meios jornalísticos, "o surgimento de um entretenimento ao mesmo tempo agradável e facilmente digerível, que tende a substituir a captação do real por aquilo que está pronto para o consumo e que mais desvia para o consumo de estímulos destinados a distrair do que leva para o uso público da razão" (Habermas, op. cit., p. 198-202).

Com isso, o jornalismo se tornou um dos eixos de sustentação da indústria cultural. O público leitor foi se convertendo em mercado de consumidor de informação sobre atualidades. A formação da opinião passou da condição de processo político vivido como idéia e ideologia por intermédio da imprensa à função dos processos de consumo visando orientação prática ou funcional em meio a um vasto e abrangente sistema de comunicações ordenado como indústria cultural.

Como escreve Ciro Marcondes Filho, "o jornalismo que se fazia antes disso era de pequeno porte, com centenas de títulos diferentes, e funcionava como uma espécie de produto informativo num grande mercado de opiniões". A variedade de opiniões permitia que se agisse sobre o processo político, as pessoas alimentassem boatos e, mal ou bem, se articulasse uma opinião pública.

O esclarecimento produzido pela imprensa era na maior parte retórico, porque nem antes nem agora a informação deixou de ser usada com objetivos espúrios, mas havia, sobretudo 
pela via dos veículos sérios. A notícia, em algum grau, impunha-se politicamente e, mais tarde, como instrumento de acesso mais pluralista ao conhecimento sobre o que acontecia à sociedade.

Conforme o capitalismo foi se expandindo quando da virada para o século $X X$, radicalizando a competição e formando mercados massivos, isso se alterou, de modo que, atualmente, sua situação tende, em vez disso, a fazer do jornalismo "um meio de regulação e integração sistêmica à sociedade". Os processos de formação da opinião e síntese do conhecimento ordinário não somem de vista, mas retiram-se para os bastidores e já não refletem uma opinião formada em condições de baixa pressão.

Atualmente, eles estão subordinados à publicidade de opiniões ou opinião publicada dos grupos de pressão mais organizados. As políticas editoriais são cada vez mais influenciadas não apenas pelos resultados e análises das pesquisas de mercado, mas pelos conceitos e práticas mercadológicas, a ponto de a habilidade em saber fazer negócios ter se tornado um elemento altamente valorizado neste mercado profissional ${ }^{17}$.

$\mathrm{O}$ jornalismo, ninguém discute, continua sendo uma prática formadora de conhecimento comum em escala de massas e, portanto, um fator de esclarecimento. $\mathrm{O}$ conceito de informação com que ele passou a operar no século passado é algo que não se esgota no plano dos fatos, sempre que o sujeito não perde o poder de reflexão sobre a matéria. $\mathrm{O}$ relato noticioso sobre os fatos é um produto cultural que, contrariamente ao pretendido às vezes, "certamente possibilita um melhor juízo a seu respeito do que quaisquer longos discursos [doutrinários]"18.

Desde o affaire Dreyfus até o escândalo Watergate, embora esporádico não deixa de ser notável o influente papel dos meios de informação no controle da administração dos assuntos públicos. Quem não é capaz de compreender isso, precisa saber que isso se acha em profundo conflito com os estereótipos ingênuos que julgam os meios de informação como simples agências de reprodução do sistema de dominação estabelecido ${ }^{19}$.

Contudo, isso não pode ser entendido de maneira abstrata. O conhecimento público e imediato que as atividades jornalísticas nos proporciona precisa ser situado em seus diversos contextos de intervenção, abstraído dos quais é uma categoria abstrata e sem sentido histórico determinado. O fenômeno, noutros termos, não pode, no caso, ser entendido fora da tendência "às informações se converterem em bens de consumo, produzirem um certo prazer, ou melhor: um prazer substitutivo, entre aqueles para as quais estão destinadas" 20 .

Durante muito tempo criticou-se o jornalismo por certas características que, na verdade, lhe são intrínsecas, enquanto for jornalismo e, assim, categoria da era capitalista. A fragmentação, efemeridade, superficialidade, imprecisão, personalismo, estereotipia, seletividade da notícia, para ilustrar, não são expedientes para manter a alienação da consciência. A notícia é uma forma de informação mas, antes disso, é uma categoria oriunda da economia de mercado e que se elabora de acordo com a dinâmica do capitalismo. A cobertura e a reportagem jornalísticas, sempre que não se resumem a amontoados de notícias, preservando a profundidade e/ou a espontaneidade, provavelmente transcendem esse registro, mas ainda hoje são formas possuidoras de menor ressonância no ambiente espiritual de nosso tempo.

Da categoria, portanto, não se deve esperar mais do que ela pode oferecer: pretender que ela passe sem as feições acima citadas seria o mesmo que pedir pelo seu desaparecimento. A reivindicação, é claro, pode ser feita e defendida: o jornalismo não necessariamente morreria com seu atendimento, mas não é isso o que está em questão neste artigo. O principal aqui é sublinhar que o problema do jornalismo não é a particularidade do saber que ele difunde, mas antes a forma como ele a elabora, dependente, em última instância, do movimento da indústria cultural.

Conforme o capitalismo avança e se enraíza na vida humana, tudo isso, aliás, não faz senão se aprofundar, e prova disso são não apenas a crescente abstração do processo de elaboração desse saber quanto à própria vinculação desse saber aos esquemas mais artificiosos com que a sua prática articula o mundo para a consciência. A reflexão crítica em jornalismo começa pelo reconhecimento de suas categorias fundamentais, listadas mais acima, e se prolonga com o estudo e análise de suas excrescências passíveis de alguma problematização prática, como o são o sensacionalismo, o partidarismo, a espetacularização, o oficialismo, o vedetismo e a artificialização (criação de factóides) ${ }^{21}$. 
O problema, para ela, portanto, não é o presente declínio dos jornais impressos, porque não é o veículo que define uma prática, e sim o contrário. O jornalismo é função de determinadas relações sociais, cujos suportes acompanham o seu progresso tecnológico, tanto quanto os demais eixos. A linha de força que as puxa, contudo, não é sem sentido objetivo: ela é, no caso, a linha de força da indústria cultural, cujos efeitos nesse campo, na atualidade, vão além da diluição generalizada, embora não total, da distinção entre jornalismo sério e leve (sensacionalista) que se origina do século XIX.

Neste novo momento, virtualmente pósmoderno ${ }^{22}$, acontece de o jornalismo redirecionar seu foco e se reestruturar em valores, passando a mesclar-se com a publicidade e a se orientar no sentido do entretenimento. Os veículos que não se sabe mais se praticam o jornalismo ou o show de variedade se projetam numa nova esfera, que a falta de conceito melhor, se chama de infoentretenimento ${ }^{23}$.

Neste âmbito, as categorias pelos quais se orientava (sério e leve), tomadas isoladamente, caducam. As empresas passam a ir para além do mero empacotamento de notícias para colocação no mercado. A possibilidade de interferir na realidade e fabricar deliberadamente certos fatos, entrevista tantas vezes no passado ${ }^{24}$, deslancha. O jornalismo se deixa envolver pelo movimento mercadológico mais amplo de criação e difusão de factóides que toma conta da sociedade e se manifesta em todos os campos, mas, sobretudo, no noticiário sobre as chamadas celebridades.

Dizendo isso, ninguém aqui está pensando que os jornais, em algum momento, limitaram-se a reproduzir fatos, porque fatos (jornalísticos) só há a partir do momento em que o processo social se imobiliza (parcialmente) pela ação da notícia, da reportagem, da cobertura jornalística. Os acontecimentos (jornalísticos) são tais porque o jornalismo assim os construiu para a consciência social: eles não são o real mas, antes, uma realidade jornalística. Ainda com isso em mente, convém pesquisar e distinguir analiticamente, porém, os casos em que eles se originam da realidade (natural, histórica) e os casos em que eles se originam imanentemente apenas das necessidades da indústria jornalística, senão das estratégias com que os setores mais poderosos ou bem aparelhados a instrumentalizam, via os seus serviços e assessorias de comunicação.
Quando alguém diante de uma ocorrência fala: "chamem a imprensa", como se diz, isso significa: o ocorrido, no limite, deve ser conhecido por toda a sociedade mas, mais especificamente, a sociedade capitalista. A expressão, na realidade, significa: a sociedade capitalista ou setores dela desejam que as ocorrências em questão sejam conhecidas. As regras, o alcance e o sentido dessa profissão, no entanto, variam conforme as relações sociais, sob o impacto do contexto mais abrangente, se desenvolvem.

Agora, verificamos, acontece, cada vez mais, de os sujeitos começarem eles todos, sempre que possível, a se conduzir de modo a serem notícia ou tentarem criar, via os esquemas da indústria cultural, fatos jornalísticos. O fetichismo da mercadoria se amplia e toma conta de sua ação de uma forma mais criativa: os fatos "são cada vez mais ou provocados pela própria imprensa ou construídos para que a imprensa os utilize"25. Os princípios do marketing se transladam para o plano individual, retirando a prática da publicity do segundo plano a que lhe havia relegado o desenvolvimento das relações públicas oriundas das organizações.

A convergência dos meios de comunicação e o seu reprocessamento ou apropriação em bases cada vez mais moleculares observados atualmente via as redes sociais da internet não são, por isso, senão a base de amparo e socialização da chegada à maturidade da cultura de consumo e do saber mercadológico, do império da indústria cultural e do triunfo do sistema capitalista.

Nesse contexto, o conhecimento público se esvai de conteúdo conscientizador em termos políticos, econômicos e intelectuais e, no limite, se reduz em sentido à diversão, passando a girar em torno de referências fantasmagóricas, cujo único ou principal meio de contato com a experiência cotidiana tende a ser o do consumo mercantilizado. Porém, não é só: esse fenômeno se explica e complementa pelo fato de, agora, o problema enfrentado pelo indivíduo não ser mais a falta, mas antes o excesso de informação.

A crescente capilarização das fontes de informação, exponenciada sempre mais pela internet, é o indicador mais notável de um processo cujo efeito principal, do ponto de vista geral, talvez seja a paralisação de sua apropriação criativa e concreta, o bloqueio da elaboração produtiva do conhecimento por parte do indivíduo $^{26}$. 


\section{Considerações finais}

Quem considera o conhecimento público ou saber cotidiano, precisa notar, de todo modo, que ele varia conforme a história e que hoje ele não se baseia mais na tradição religiosa, na formação cultural, no movimento cívico ou mesmo na pura e simples informação jornalística sobre a realidade histórica. Os novos saberes ordinários, com exceção da informação sobre os negócios, separam-se da hipoteca burguesa e são, agora, sobretudo os agenciados pelo sistema da indústria cultural: a psicologia de vendas, as relações públicas, a estética aplicada, as finanças individuais, a saúde mercantil, a automobilística, a gastronomia, o turismo, a moda... - enfim: tudo para o que, em conjunto, os americanos cunharam os termos marketing e, em reação, consumerismo, entre os anos 1930 e o final dos anos 1960.

\section{Quem considera o conhecimento público ou} saber cotidiano, precisa notar, de todo modo, que ele varia conforme a história e que hoje ele não se baseia mais na tradição religiosa, na formação cultural, no movimento cívico ou mesmo na pura e simples informação jornalística sobre a realidade histórica.

O jornalismo, vimos, se sujeitou à prática da indústria cultural e, por essa via, converteu-se em empresa que, mesmo quando não faltam os fatos ou estes não são reclamados, acostumou-se a criálos para o mercado, interferindo notavelmente em todo esse movimento. As empresas, agora, têm de fabricar fatos jornalísticos, fornecendo ou não à vida um pretexto imediato para tanto, visto que serem negócio que não pode parar, para aguardar a natureza ou a história. $\mathrm{O}$ conhecimento comum está se tornando oriundo de um processo cada vez menos espontâneo e mais artificioso, provindo de um movimento em que a curiosidade é indissociável da ambição mercantil e os chamados "fatos brutos" vão ficando sempre menos presentes.

Diante disso e para concluir, convém notar, por um lado, que o principal, nisso tudo, não deveria ser visto pela ótima da manipulação, pois antes expressa uma vontade de saber e os desejos de poder da coletividade a ele subordinada. De outro, observaríamos que essa vontade coletiva, subjacente ou oculta nesse processo, não é mais forte do que suas contradições. A crítica não é monopólio a que apenas a atividade teórica pode reclamar, oriunda, como é, de um processo histórico que não cessa de opor seus sujeitos uns aos outros ${ }^{27}$. A força que ela for capaz de exercer na reflexão será sempre uma função mediadora da forma como ela é acionada na práxis, não sendo exceção o campo do jornalismo. A profundidade e o resultado poderão ser questionados, mas ninguém negará que hoje, como antes, embora de modo distinto e alcance variável, o pluralismo opiniático segue encontrando na variedade de seus veículos uma agência para, expressandose em dobra, renovar o cunho constitutivamente conflitivo, senão explosivo do cosmo capitalista e, dessa forma, realimentar as fontes da atividade crítica em meio ao modo de vida moderno.

Como diz Adorno, "sempre que um fenômeno é criticado, não importa o quanto é particular", insurgimo-nos contra a renúncia a uma capacidade moral e intelectual cuja falta "obstrui a transição da sociedade para um estágio mais avançado" $^{\prime 28}$. De resto, o fato é que o processo vital e a espontaneidade criadora (às vezes destrutiva) continuam com forças para rasgar o tecido cerrado em que se vai convertendo o mundo e fazer irromper a vida e a história nas agências de formatação da consciência social em que se converteram os veículos e empresas jornalísticas. Os sinais de utopia que todo esse noticiário medíocre sobre, por exemplo, a vida das celebridades representa têm de enfrentar diariamente não apenas a irrupção da fatalidade individual, igualmente festejada por ele, mas a invasão da realidade histórica e natural mais abrangente, que devolve a essa prática da indústria cultural, por mais artificializada que esteja, o contato bruto com o mundo da vida cotidiana em toda a sua complicação e inusitado.

Lady Diana e Ayrton Senna movimentam o negócio dos factóides até que lhe sobrevêm o acidente fatal, objeto de noticiário não menos sensacional. As pessoas acompanham fascinadas a cobertura da vida dos famosos ou as peripécias da repórter que se aventura no fundo do mar. Nenhuma delas deveria pensar, porém, que está a salvo da catástrofe natural, do colapso econômico ou do atentado terrorista, apenas porque consome o mundo como espetáculo, como insinua a recepção distanciada promovida por sua dependência ao movimento da indústria cultural.

Adorno referiu-se várias vezes à presença de um olhar micrológico que, enigmaticamente, 
escapa ao sistema e revela-nos um mundo tal como ele não deseja ser visto e vivenciado ${ }^{29}$. A prática da indústria cultural não está isenta de sua manifestação, e o espaço privilegiado em que isso intervém e é elaborado, junto do que deriva dos conflitos históricos, parece-nos ser o que hoje se conserva como sendo o próprio da atividade jornalística espontânea e criadora.

A circunstância de seu exercício estar cada vez mais fundido com aquela prática não a blinda aos acidentes naturais e aos antagonismos humanos - por isso, sempre que possuir um elemento espontâneo, o jornalismo poderá ensejar um conhecimento potencialmente emancipatório para o indivíduo numa sociedade prisioneira do fetiche da mercadoria, sobretudo se encontrar elaboração epistêmica e, portanto, esclarecimento sensível e intelectual em uma ação séria e responsável, necessariamente auxiliada por alguma mediação jornalística.

\section{REFERÊNCIAS}

ADORNO, Theodor. Bajo el signo de los astros. Barcelona, Laia, 1986. Press, 1998.

Critical models. Nova York: Columbia University

. Educação e emancipação. São Paulo: Paz e Terra, 1988.

. History and freedom. Oxford: Polity Press, 2006.

. Introducción a la sociologia., Barcelona: Gedisa, 1996.

ADORNO, Theodor. \& Horkheimer, Max. Dialética do esclarecimento. Rio de Janeiro: Zahar, 1985.

ALBERTOS, José. El ocaso del periodismo. Barcelona: CIMS, 1997.

ANGEL, Norman. The press and the organisation of society. Londres: Labour Press, 1922.

ARBEX, José. Showrnalismo. São Paulo: Casa Amarela, 2001. BERRY, David; THEOBALD, John. (Orgs.). Radical mass media criticism. Dallas: Black Rose, 2006.

BOURDIEU, Pierre. Sobre a televisão. Rio de Janeiro: Zahar, 1997.

BURKE,Peter. Uma história social do conhecimento. Rio de Janeiro: Zahar, 2003.

DRÖGE, Franz. Wissen ohne Bewusstsein. Frankfurt: Fisher, 1972.

GENRO, Adelmo Filho. O segredo da pirâmide. Porto Alegre: Tchê, 1987.

GOULDNER, Alvin. La dialéctica de la ideología y la tecnología. Madri: Alianza, 1978.

GRAMSCI, Antonio. Maquiavel, a política e o estado moderno. Rio de Janeiro: Civilização Brasileira, 1980.

HABERMAS, Jürgen. Mudança estrutural da esfera pública. Rio de Janeiro: Tempo Brasileiro, 1984.

HARTLEY, John. Popular reality: journalism and popular culture. Londres: Arnold, 1996.

KARAM, Francisco. A ética jornalística e o interesse público. São Paulo: Summus, 2004.
KRAUS, Karl. En esta gran época. Buenos Aires: Zorzal, 2008. LIPPMANN, Walter. Public Opinion. New York: Harcourt, Brace, 1922.

MARCONDES, Ciro. Jornalismo fin-de-siècle. São Paulo: Scritta, 1993.

MARSHALL, Leandro. O jornalismo na era da publicidade. São Paulo: Summus, 2003.

MCMANNUS, James. Market-driven journalism. Thousand Oaks (CA): Sage, 1994.

MEDITSCH, Eduardo. O conhecimento do jornalismo. Florianópolis: Editora da Ufsc, 1992.

MILL, Stuart. Sobre la libertad. Buenos Aires: Aguilar, 1954.

PARK, Robert. A notícia como forma de conhecimento [1940]. In: Charles Steinberg (Org.) Meios de comunicação de massa. São Paulo: Cultrix, 1972.

RIBEIRO, Jorge. Sempre alerta. São Paulo: Brasiliense, 1995.

RÜDIGER, Francisco. Crítica. In: Ciro Marcondes Filho (Org.). Dicionário da Comunicação. São Paulo: Paulus, 2009, p. 83-84.

SCHUDSON, Michael. Discovering the news. Nova York: Basic Books, 1978.

SELDES, George: Lords of the Press. Nova York: Blue Ribbon, 1938.

SERVA, Leão. Jornalismo e desinformação. São Paulo: Senac, 2001. SINCLAIR, Upton. The brass check. Pasadena (CA): Edição do Autor, 1920.

SLOTERDIJK, Peter. Critique of cynical reason. Londres: Verso, 1988.

STEINERT, Heinz. Culture Industry. Oxford: Blackwell, 2003.

WOLF, Mauro. As teorias da comunicação. Lisboa: Presença, 1987.

WOLTON, Dominique. Penser la communication. Paris: Flammarion, 1998.

WUTTKE, Heinrich. Die Deutschen Zeitschriften und die Entestehung der Öffentlichen Meinung, 1866 - trad. francesa: Le fond des reptiles. Paris: Decaux et Dreyfous, 1877.

\section{NOTAS}

1 Adorno, T. \& Horkheimer, M. Dialética do esclarecimento. Rio de Janeiro: Zahar, 1985, p. 15.

2 O criticismo proposto nestas páginas é o de uma reflexão imanente à situação histórica, a nossa, e não o de uma atitude abstrata e propositiva em relação ao jornalismo. A crítica é uma atividade que costuma ser vista em termos de confronto com seu objeto, senão de oposição a ele, em nome de certos ideais. O problema é que tal atitude caduca totalmente a partir do momento em que não há ponto de apoio alternativo para ela fora do que está na consciência reflexiva de uma minoria pensadora da cultura e da história, como é o caso quando a prática da indústria cultural se converte em sistema.

3 Adorno, T. Bajo el signo de los astros. Barcelona, Laia, 1986, p. 120-121. Cf. Franz Dröge: Wissen ohne Bewusstsein. Frankfurt: Fisher, 1972. Marino Livolsi elabora o ponto com base em uma abordagem sociológica formal em Manuale di sociologia della comunicazione. Bari: Laterza, 2000.

4 Por conhecimento não é entendida aqui a síntese ou resultado especializado da relação sujeito e objeto, conforme estabelece a gnosiologia tradicional. A expressão refere-se, 
antes de tudo, à consciência imediata de compartilhamento de um mundo: ao conjunto de referências práticas e intelectuais que estrutura e orienta, só ás vezes inovadoramente, a conduta e o pensamento cotidianos de uma coletividade em um dado momento histórico.

5 Habermas, Jürgen. Mudança estrutural da esfera pública. Rio de Janeiro: Tempo Brasileiro, 1984, p. 215. A obra é objeto de várias discussões em Craig Calhoum (Org.) Habermas and the public sphere. Cambridge (MA): MIT Press, 1992.

6 Cf. Schudson, Michael. Discovering the news. Nova York: Basic Books, 1978.

7 Mill, Stuart. Sobre la libertad. Buenos Aires: Aguilar, 1954, p. 136.

8 Angel, Norman. The press and the organisation of society. Londres: Labour Press, 1922, p. 12. Gramsci, Antonio. Maquiavel, a política e o estado moderno. Rio de Janeiro: Civilização Brasileira, 1980, p. 116. Cf. Heinrich Wuttke: Die Deutschen Zeitschriften und die Entestehung der Öffentlichen Meinung, 1866 - trad. francesa: Le fond des reptiles. Paris: Decaux et Dreyfous, 1877. Upton Sinclair: The brass check. Pasadena (CA): Edição do Autor, 1920. George Seldes: Lords of the Press. Nova York: Blue Ribbon, 1938. Karl Kraus: En esta gran época. Buenos Aires: Zorzal, 2008. Sobre Kraus, ver o artigo de John Theobald, em Berry, D. \& Theobald, J. (Orgs.): Radical mass media criticism. Dallas: Black Rose, 2006.

9 Levando em conta esse aspecto, torna-se mais fácil entender porque o principal elemento inovador da pesquisa posterior sobre o jornalismo, inclusive dentro do paradigma dominante, foi a revelação e análise das estruturas e mecanismos que agenciam seu pretendido poder no interior do campo jornalístico (cf. Wolf, Mauro. As teorias da comunicação. Lisboa: Presença, 1987, p. 157225. Pierre Bourdieu empregou variante do enfoque em Sobre a televisão. Rio de Janeiro: Zahar, 1997). Os estudos de newsmaking, referimo-nos a eles,merecem atenção sobretudo pela explicação do contexto mais imediato de criação do material jornalístico, mas isso não deveria nos fazer perder de vista seu caráter de mediação de processos sociais e históricos mais abrangentes. Para nós, entendido por nós como sendo o da indústria cultural, é capaz de explicar sua inserção e sentido no processo social e histórico mais abrangente.

${ }^{10}$ Park, Robert. A notícia como forma de conhecimento [1940]. In: Charles Steinberg (Org.) Meios de comunicação de massa. São Paulo: Cultrix, 1972.

${ }^{11}$ Cf. Adelmo Genro Filho: O segredo da pirâmide. Porto Alegre: Tchê, 1987. Eduardo Meditsch: O conhecimento do jornalismo. Florianópolis: Editora da Ufsc, 1992. Francisco Karam: A ética jornalística e o interesse público. São Paulo: Summus, 2004.

${ }^{12}$ Genro, A., op. cit, p. 172. As práticas jornalísticas funcionam como mediação estruturadora da consciência social, mas por outro lado não se deve esquecer que elas são, por sua vez, mediadas por várias estruturas sociais históricas. O presente ensaio sublinha sua subsunção à racionalidade mercantil e, mais recentemente, mercadológica, mas mesmo esse processo precisa ser visto sem reducionismo, como nos alerta, ainda que equivocadamente, em nosso ver, Adelmo Genro. A cobertura de inúmeros acontecimentos, sobretudo políticos e criminais, revela, por exemplo, que esse racionalismo ainda hoje explora estruturas e atitudes bem arcaicas como o é, para citar um caso, a curiosidade intelectual, ainda que mórbida, despertada por um fato enigmático passível de agenciamento narrativo (ainda que fragmentariamente). Atualmente, “quase tudo está a serviço da informação" (Benjamin), mas ainda resta, mesmo em meio a tanto, "algo a serviço da narrativa" (cf. Hartley, John. Popular reality: journalism and popular culture. Londres: Arnold, 1996).

${ }^{13}$ A consciência crítica não nega que se formem grupos de interesses e que esses, possuindo ou não seus próprios meios, eventualmente os usem para tentar manipular a visão do público - mas daí não tira a conclusão de que esse emprego costuma ser bem sucedido e que, na hipótese de ser o caso, o resultado é puro e simples efeito daquela manipulação.

${ }^{14} \mathrm{Cf}$. Peter Burke: Uma história social do conhecimento. Rio de Janeiro: Zahar, 2003.

${ }^{15}$ Cf. Peter Sloterdijk: Critique of cynical reason. Londres: Verso, 1988.

${ }^{16}$ Ribeiro, J. Sempre alerta. São Paulo: Brasiliense, 1995.

${ }^{17}$ Marcondes, C. Jornalismo fin-de-siècle. São Paulo: Scritta, 1993, p. 123-144. Cf. James McMannus: Market-driven journalism. Thousand Oaks (CA): Sage, 1994. Leandro Marshall: O jornalismo na era da publicidade. São Paulo: Summus, 2003.

${ }_{18}$ Adorno, T. Educação e emancipação. São Paulo: Paz e Terra, 1988, p. 79.

${ }^{19}$ Gouldner, A. La dialéctica de la ideología y la tecnología. Madri: Alianza, 1978, p. 207.

${ }^{20}$ Adorno, T. Introducción a la sociología, p. 69. Em resumo, importante "não é o fato dos cidadãos terem a informação adequada (nem a existência de alguma forma de comunicação não distorcida), mas nossa habilidade em trabalhar com o mundo e, ao mesmo tempo, apropriarmo-nos dele individualmente". Para Adorno, isso era algo que, "embora ainda possa ser alcançado mesmo no capitalismo", pode "não ter sua sobrevivência continuada" (Heinz Steinert: Culture Industry. Oxford: Blackwell, 2003, p. 24-25).

${ }^{21}$ Pioneiros no exame dessa última categoria, sabe-se, foram Walter Lippman (Public opinion, 1922) e Daniel Boorstin (The image, 1962).

${ }^{22}$ A contraposição entre jornalismo moderno e pós-moderno poderia tomar como ponto de partida as concepções de relato que lhe subjazem: lá focado no objeto, no relato do vivido pelo sujeito, aqui focado no sujeito, no relato do que é por ele vivenciado (o repórter como protagonista dos fatos ou ações em foco na notícia ou matéria).

23 Albertos, J. El ocaso del periodismo. Barcelona: CIMS, 1997. José Arbex: Showrnalismo. São Paulo: Casa Amarela, 2001.

${ }^{24}$ A Guerra Hispano-Americana de 1898, supostamente detonada pelos jornais de William Randolph Hearst, é, sem dúvida, um ponto de partida desse movimento.

${ }^{25}$ Marcondes Filho, op. cit., p. 129.

${ }^{26}$ Cf. Dominique Wolton: Penser la communication. Paris: Flammarion, 1998, p. 189-233. Leão Serva: Jornalismo e desinformação. São Paulo: Senac, 2001.

${ }^{27}$ Cf. Rüdiger, F. Crítica. In: Ciro Marcondes Filho (Org.). Dicionário da Comunicação. São Paulo: Paulus, 2009, p. 83-84.

28 Adorno, T. Critical models. Nova York: Columbia University Press, 1998, p. 287.

${ }^{29}$ Cf. Theodor Adorno: History and freedom. Oxford: Polity Press, 2006. 